\title{
Respiratory Distress in Full and Post Term Neonates: Prevalence, Etiologies and Outcomes in a Tertiary Health Center in Yaoundé
}

\author{
Didi Stanine Mefo Kue ${ }^{1}$, Jeannette Epee Ngoue ${ }^{2,3}$, Annie Carole Nga Motaze,4, \\ Aude Sabine Nanfack ${ }^{5}$, Anne Esther Njom-Nlend1,3,4*
}

${ }^{1}$ Higher Institute of Medical Technology Nkolondom, Department of Clinical Sciences, University of Douala, Douala, Cameroon ${ }^{2}$ Department of Pediatrics, Faculty of Medicine and Biomedical Sciences, Yaoundé, Cameroon

${ }^{3}$ Cameroon Society of Perinatal Medicine, Yaoundé, Cameroon

${ }^{4}$ Essos Hospital Centre, National Social Insurance Fund, Yaoundé, Cameroon

${ }^{5}$ Ministry of Economy and Development, Yaoundé, Cameroon

Email: ^anne.njom@gmail.com

How to cite this paper: Kue, D.S.M., Ngoue, J.E., Motaze, A.C.N., Nanfack, A.S. and Njom-Nlend, A.E. (2021) Respiratory Distress in Full and Post Term Neonates: Prevalence, Etiologies and Outcomes in a Tertiary Health Center in Yaoundé. Open Journal of Pediatrics, 11, 351-359. https://doi.org/10.4236/ojped.2021.113032

Received: February 10, 2021

Accepted: July 23, 2021

Published: July 26, 2021

Copyright $\odot 2021$ by author(s) and Scientific Research Publishing Inc. This work is licensed under the Creative Commons Attribution International License (CC BY 4.0).

http://creativecommons.org/licenses/by/4.0/

\section{(c) (i) Open Access}

\begin{abstract}
Introduction: Respiratory pathologies are top listed amongst neonatal morbidities. Our objective was to describe the clinical features, causes and treatment of respiratory distress (RD) in full and post term neonates in a tertiary health center in Yaoundé, the Essos Hospital Centre (EHC). Patients and Method: This was a retrospective study. Full/post term neonates with $\mathrm{RD}$ from January 2017-December 2018 were included. Main parameters: incidence of $\mathrm{RD}$, etiologies, risk factors for severity and mortality. Results: We included 186 neonates among 2312 newborn babies. The $\mathrm{RD}$ prevalence rate was $8 \%$. Sex ratio of 2.15 was favoring male, median gestational age of 38 weeks. Clinical signs of RD were dominated by a Silverman score above $4 / 10$ in $64 \%$. Main etiologies were pneumonia $(44 \%)$, followed by transient tachypnea (35.4). Perinatal asphyxia $(\mathrm{OR}=9.412, \mathrm{P}=0.005)$ and cyanosis $(\mathrm{OR}=$ 6.509; $\mathrm{P}<0.001)$ were worsening $\mathrm{RD}$, while caesarian section was protective $(\mathrm{OR}=0.412 ; \mathrm{P}=0.050)$. Mortality rate $(\mathrm{MR})$ was $10.4 \%$. Therapeutic measures briefly consisted in oxygen therapy for $98.9 \%$ of patients and probabilistic antibiotic therapy. Conclusion: Neonatal pneumonia was the preeminent etiology of RD in this population; the MR was high.
\end{abstract}

\section{Keywords}

Neonatal Infection, Respiratory Distress, Term Neonates, Transient

Tachypnea, Respiratory Distress, Yaoundé 


\section{Introduction}

Respiratory distress is a common condition in neonates requiring admission in a neonatal care unit (NCU) [1]. It can occur in both preterm and full-term neonates affecting both morbidity and mortality rates [2] [3]. The main medical diagnoses related to these conditions are transient tachypnea, meconium aspiration syndrome, respiratory distress syndrome also known as hyaline membrane disease and pneumonia [4]. Due to increasing meconium inhalation, respiratory distress syndrome, although seen primarily in preterm babies, is also seen increased in full-term neonates and deserves more attention [5].

Sparse data of surgical causes of $\mathrm{RD}$ are available in sub-Saharan Africa, maybe due to shortage in antenatal diagnosis, including limited performance of routine third trimester echographies during pregnancy plus low capacity of clinical diagnosis in the labor room. Consequently, many $\mathrm{RD}$ cases are medical pulmonary diseases and/or due to congenital cardiovascular conditions [4]. In recent years, the widely used antenatal corticosteroids have resulted in a reduction of hyaline disease especially in preterm babies. However, in parallel the increasing rate of caesarian section has led to more recorded cases of RD in full-term neonates [6]. In Cameroon, the General Hospital-Douala team, JN Tochie et al. in 2016 , reported that RD was representing the main cause of neonatal admission (47.5\%) in the NCU [7]. Elsewhere, in Nepal, RD contributed to a third of NCU admissions, with an incidence around 4\% [8]. Overall, data remain scarce in low resource settings especially for full term neonates with an incidence rate recorded between $1.2 \%$ to $7.2 \%$ in term live births. In addition, RD morbidity in low resource settings seems to be greater compared to data of high-income countries [9]. As epidemiological trends show an increasing rate of RD in full-term newborns [10] [11], we designed this study with the primary objective to assess and describe clinical features, causes and management of RD in full and post-term neonates in a tertiary facility in Yaoundé.

\section{Method}

\subsection{Type, Site, Duration and Population}

We conducted a cross sectional retrospective and analytical study over a 24 month-period at Essos Hospital Centre. Neonates $\geq 37$ weeks, aged less than 28 days were included, assuming admission in NCU for RD during the first 48 hours of life.

\subsection{Procedure}

\subsubsection{Data Collection}

Files of neonates eligible were extracted from the neonatal inpatient registry. Data collection lasted for 6 months from January to June 2019. For each newborn, the following variables were recorded: maternal sociodemographic characteristics, clinical features, treatment and early outcomes. Clinical assessment of severity was based on Silverman score quotation. In this study RD was defined 
as the presence of abnormalities of $\mathrm{F}$ (frequency of breathing), W (work), $\mathrm{V}$ (ventilation), O (oxygenation). RD with Silverman score above 4 was considered as severe. To investigate the RD in this NCU, file analysis included: clinical assessment $=$ rate of breathing, cyanosis, and Silverman score and pulse oximetry. Other investigations recorded were full blood count, C-reactive protein, and chest radiography as soon as the baby was transportable. The key conditions retained for diagnosis in our study based on clinical and chest X-ray were: transient tachypnea (rapid onset of RD after birth with superficial tachypnea with favorable outcomes within 24 to 48 hours), meconium aspiration syndrome (established in case of RD in full or post-term newborns with a story of perinatal asphyxia and meconium stained amniotic fluid), congenital pneumonia (in the presence of isolated RD or associated with any feature of neonatal sepsis), respiratory distress syndrome (defined as onset of $\mathrm{RD}$ before 24 hours of life without honey moon period with lung (thorax) retraction), pulmonary hypertension in case of RD with critical cyanosis with no criteria for infection, congenital heart disease (in case of RD plus heart murmur or abnormalities at echocardiography); surgical conditions were suspected in presence of asymmetry at clinical auscultation and/or clinical improvement at crying plus results of medical imaging. Each diagnosis suspected was confirmed by a senior pediatrician in the medical file of the patient after viewing of the chest X-ray and/or cardiac echography done following admission.

\subsubsection{Data Analysis}

After collection, data were transferred in software Cs pro version 7.1 word processing and tables were using Microsoft Word and Excel version 2013 software, then analyzed using software Stata version 13. Descriptive data and etiologies were rated using frequency. The Chi-square test was used for the independence test, the Fisher exact test was used alternately when the assumptions for the Chi-square test were not satisfied. In multivariate analysis, the logistic regression model was used to estimate the Odds Ratio (OR) and their 95\% confidence intervals.

\section{Results}

From January 2017 to December 2018, 2312 newborn babies were admitted in NCU of Essos hospital Centre of which 186 presented an RD giving a prevalence rate of $8 \%$.

\subsection{Sociodemographic Characteristics}

Median maternal age was 29 years with interquartile range $(24-32)$. The majority were multiparous, with parity ranging from 1 to 8 . The median gestational age of the babies was 38 weeks, with $11.8 \%$ of them postmature. At birth, $30.6 \%$ of them were resuscitated and their admission in NCU occurred at a median age 7.25 hours of life. Admissions of male were representing $68.3 \%$ of the sample giving a sex-ratio of 2.15 (see Table 1 ). 
Table 1. Distribution of respiratory distress according to maternal and neonatal sociodemographic characteristics.

\begin{tabular}{|c|c|c|}
\hline & Number (186) & Percentage (\%) \\
\hline \multicolumn{3}{|c|}{ Age at admission of neonate in hours } \\
\hline$[1-7]$ & 138 & 74.2 \\
\hline$[8-14]$ & 37 & 19.9 \\
\hline$>14$ & 11 & 5.9 \\
\hline \multicolumn{3}{|l|}{ Gender } \\
\hline Male & 127 & 68.8 \\
\hline Female & 59 & 31.7 \\
\hline \multicolumn{3}{|l|}{ Gestational age } \\
\hline$[37-42]$ & 164 & 88.2 \\
\hline$>42$ & 22 & 11.8 \\
\hline \multicolumn{3}{|l|}{ Maternal age } \\
\hline$[15-24]$ & 58 & 31.2 \\
\hline$[25-34]$ & 109 & 58.6 \\
\hline$[35-45]$ & 19 & 10.2 \\
\hline \multicolumn{3}{|l|}{ Parity } \\
\hline 1 & 83 & 44.6 \\
\hline$[2-4]$ & 94 & 50 \\
\hline$>4$ & 10 & 5.4 \\
\hline \multicolumn{3}{|l|}{ Maternal morbidities } \\
\hline Hypertension & 12 & 6.5 \\
\hline Gestational diabetes & 12 & 6.5 \\
\hline Maternal infection & 37 & 19.9 \\
\hline
\end{tabular}

\subsection{Clinical Characteristics and Main Etiologies}

Amongst the neonates included, almost 9 of 10 had an Apgar score below 7 at 5 $\mathrm{mn}$ of life and 2 of 3 (64\%) had a Silverman score quoted above 4 upon admission. Clinical cyanosis was present in $54 \%$, with normal pulse oximetry above $94 \%$ for $8.1 \%$ (Table 2). The main etiologies of RD in this setting were pneumonia (44\%), followed by transient tachypnea (35.4\%) and meconium aspiration syndrome (16.6\%). Surgical causes were few, representing $1.6 \%$ of cases (see Table 3).

\subsection{Management, Outcomes and Associated Factors}

Nasal oxygen was widely provided to the neonates with antibiotics as adjunct using 2 drugs given by intravenous infusion. Supportive treatment included parenteral infusion of glucose and electrolytes during the first days of treatment. In this setting, the mortality rate was $10.2 \%$. Not surprisingly, being cyanotic increased the risk of severe $\mathrm{RD}(\mathrm{OR}=6.509$; $\mathrm{P}<0.001)$; having an Apgar score below $7 / 10$ at $5 \mathrm{mn}$ increased the risk of severe $\mathrm{RD} 9$ fold $(\mathrm{OR}=9.412, \mathrm{P}=$ 
Table 2. Analysis of respiratory distress according to clinical data.

\begin{tabular}{|c|c|c|}
\hline & Number (186) & Percentage (\%) \\
\hline \multicolumn{3}{|l|}{ Cyanosis } \\
\hline Yes & 102 & 54.8 \\
\hline No & 84 & 45.2 \\
\hline \multicolumn{3}{|c|}{ Apgar Score (5th minute) } \\
\hline$\leq 7 / 10$ & 168 & 90.8 \\
\hline$>7 / 10$ & 17 & 9.2 \\
\hline \multicolumn{3}{|c|}{ Silverman Score } \\
\hline$[3-4]$ & 67 & 36 \\
\hline$[4-6]$ & 82 & 44.1 \\
\hline$>6$ & 37 & 19.9 \\
\hline \multicolumn{3}{|c|}{ Resuscitation of newborn at birth } \\
\hline Yes & 57 & 30.6 \\
\hline No & 129 & 69.4 \\
\hline \multicolumn{3}{|l|}{ Heart Pulse } \\
\hline$<110$ & 3 & 1.6 \\
\hline$[110-160]$ & 107 & 57.5 \\
\hline$>160$ & 76 & 40.9 \\
\hline \multicolumn{3}{|l|}{ Breathing rate } \\
\hline$<60$ & 16 & 8.6 \\
\hline$[60-80]$ & 139 & 74.7 \\
\hline$>80$ & 31 & 16.7 \\
\hline \multicolumn{3}{|c|}{ Pulse oxymetry upon admission \% } \\
\hline 80 & 27 & 14.5 \\
\hline$[80-94]$ & 144 & 77.4 \\
\hline$>94$ & 15 & 8.1 \\
\hline \multicolumn{3}{|l|}{ Temperature } \\
\hline Hypothermia & 1 & 5 \\
\hline Normal & 102 & 54.8 \\
\hline Hyperthermia & 83 & 44.6 \\
\hline
\end{tabular}

Table 3. Distribution of respiratory distress according to medical vs surgical etiologies.

\begin{tabular}{lcclcc}
\hline \multicolumn{2}{c}{ Medical } & \multicolumn{5}{c}{ Surgical } \\
\hline & Number $\begin{array}{c}\text { Percentage } \\
(\%)\end{array}$ & Number & $\begin{array}{c}\text { Percentage } \\
(\%)\end{array}$ \\
\hline Neonatal infection Pneumonia & $\mathbf{8 2}$ & $\mathbf{4 4}$ & $\begin{array}{l}\text { Oesophageal } \\
\text { Atresia } \\
\text { Congenital } \\
\text { diaphragmatic } \\
\text { hernia }\end{array}$ & 1 & 0.5 \\
Transient Tachypnea & 66 & 35.4 & 1 & 0.5 \\
$\begin{array}{l}\text { Meconium aspiration } \\
\text { Syndrome }\end{array}$ & 31 & 16.6 & Choanal atresia & 1 & 0.5 \\
$\begin{array}{l}\text { Pulmonary arterial } \\
\text { hypertension }\end{array}$ & 2 & 1.1 & & & \\
Respiratory distress syndrome & 2 & 1.1 & & & \\
\hline
\end{tabular}


Table 4. Factors associated with severity of respiratory distress: multivariate analysis.

\begin{tabular}{|c|c|c|c|}
\hline Severity of respiratory distress & Odds Ratio & IC $95 \%$ & P-Value \\
\hline \multicolumn{4}{|l|}{ Cyanosis } \\
\hline yes & 6.509 & $2.693-15.72$ & $<0.001^{*}$ \\
\hline \multicolumn{4}{|l|}{$\mathrm{SaO}_{2}$} \\
\hline$<80 \%$ & 4.005 & $1.178-13.6$ & $0.026^{*}$ \\
\hline \multicolumn{4}{|l|}{ Respiratory rate } \\
\hline$[60-80]$ & 2.029 & $0.542-7.581$ & 0.293 \\
\hline$>80$ & 8.914 & $0.511-122.52$ & 0.129 \\
\hline \multicolumn{4}{|l|}{ Apgar Score $5 \mathrm{mn}$} \\
\hline$<7 / 10$ & 9.412 & $1.962-45.73$ & $0.005^{*}$ \\
\hline \multicolumn{4}{|l|}{ Mode of delivery } \\
\hline Ceasarian Section & 0.412 & $0.168-0.929$ & $0.050^{*}$ \\
\hline \multicolumn{4}{|l|}{ Maternal infection } \\
\hline No & 0.522 & $0.127-2.213$ & 0.365 \\
\hline
\end{tabular}

Légend: *: significance; OR: odd ratio; P: P value inf à $0.05 ; \mathrm{CI}$ : Confidence Interval.

0.005). Lastly, neonates born by $\mathrm{C}$-section had a lower risk of severe RD than those born vaginally $(\mathrm{OR}=0.412 ; \mathrm{P}=0.050)$, as shown in Table 4 .

\section{Discussion}

This study could be a pioneering one in analyzing the profile of $\mathrm{RD}$ in neonates born after 37 weeks of gestation in Cameroon. As first finding, our rate of RD admissions in NCU of $8 \%$ was slightly higher than the global record, around 5 to $7 \%$ of term live births including data observed in Saudi Arabia and Baghdad in a tertiary level NCU of $1.64 \%-2.78 \%$ [12] [13]; these discrepancies can be explained by exclusion of post term neonates and/or inclusion in neonatal units versus maternities. On the other hand, our prevalence rate was lower than those recorded in Egypt and Karachi [3] [14], where neonates were included irrespective of gestational age. Of note, we found a preeminence of $\mathrm{RD}$ in males in our setting. This finding was consistent with two studies showing susceptibility of the male gender for RD without any clear explanation [14] [15]. With regards to the causes, pneumonia stood as the first cause of $\mathrm{RD}$ in this setting, thus confirming previous data; this is easily understandable as neonatal infection is a leading cause of morbidities and mortality in our environment [16]. In second position, transient tachypnea was posting a rate concordant with the level of practice of caesarian sections in this population, though the specific rate of elective caesarian sections was not known. In fact, this preeminent TT among this population also fits with the $10 \%$ of mothers having a history of maternal diabetes and/or foetal macrosomia [17] [18] [19]. Following TT, meconium aspiration syndrome (MAS), was the third cause of RD; unfortunately this diagnosis of MAS can lead to respiratory distress syndrome in full-term neonates and can 
be challenging to manage in absence of exogenous surfactant and bubble CPAP [20] [21]. We can attest that other causes of RD (diaphragmatic hernia, esophageal atresia, choanal atresia) were relatively scarce. This scarcity can be attributed to the delay in diagnosis and/or limited access to antenatal diagnosis; including feeble neonatal networks and low capacity of neonatal transfer. Regardless of the very limited means available for optimal management of infants with $\mathrm{RD}$ (oxygen and antibiotics), notably the lack of positive expiratory pressure known to be helpful in many cases of $\mathrm{RD}$, the mortality rate observed around $10 \%$, though high, could appear laudable in our context [22] [23]. Looking at the associated factors of severity, a surprising finding in this study was the protection conferred by caesarian sections, but we can explain this, by the fact that many C-sections were not elective but done emergently, to alleviate the risk of perinatal asphyxia thus appearing to be protective for the newborn.

\section{Limitations of the Study}

This study records some limitations due to its design. As a retrospective study, some files were lacking information for accuracy of the diagnosis and etiology. In addition, in some cases, the chest X-ray was not performed timely.

\section{Conclusion}

$\mathrm{RD}$ in neonates born after 37 weeks gestation was mainly due to neonatal infection and pneumonia; the outcome was still critical with $10.4 \%$ mortality rate due to lack of optimal management thus supporting extended access to positive expiratory pressure devices.

\section{Acknowledgements}

We are grateful to both health care providers and managers of Esssos Hospital Centre for their contributions to the data collection for this study.

\section{Funding}

No funding was received for this study.

\section{Availability of Data and Materials}

Data underlying these findings are provided in the manuscript tables and figures. Complete dataset could be provided upon reasonable request from the corresponding author. This dataset represents a core of the hospital database and may not be deposited in a public repository.

\section{Authors' Contributions}

Designed the study: DSMK and AENN Collected data JEN and ACNM. Analysed the data: ASN. Interpreted the data: DSMK and AENN. Initiated the manuscript: DSMK. Revised the manuscript: AENN. All authors read and approved the final version of the manuscript. 


\section{Ethics Declarations}

Ethics approval and consent to participate. Ethical clearance for this study was obtained from the Institutional review board (IRB) of the Essos Hospital Centre; the Hospital Directorate provided an administrative authorization; and all data were processed under strict confidentiality and privacy by using unique identifiers.

\section{Consent for Publication}

N/A.

\section{Conflicts of Interest}

The authors declare that they have no competing interests.

\section{References}

[1] Baseer, K.A.A., Mohamed, M. and Abd-Elmawgood, E.A. (2020) Risk Factors of Respiratory Diseases among Neonates in Neonatal Intensive Care Unit of Qena University Hospital, Egypt. Annals of Global Health, 86, 22. https://doi.org/10.5334/aogh.2739

[2] Liu, J., Yang, N. and Liu, Y. (2014) High-Risk Factors of Respiratory Distress Syndrome in Term Neonates: A Retrospective Case-Control Study. Balkan Medical Journal, 31, 64. https://doi.org/10.5152/balkanmedj.2014.8733

[3] Gallacher, D.J., Hart, K. and Kotecha, S. (2016) Common Respiratory Conditions of the Newborn. Breathe, 12, 30-42. https://doi.org/10.1183/20734735.000716

[4] Liszewski, M.C., Stanescu, A.L., Phillips, G.S. and Lee, E.Y. (2017) Respiratory Distress in Neonates: Underlying Causes and Current Imaging Assessment. Radiologic Clinics of North America, 55, 629-644. https://doi.org/10.1016/j.rcl.2017.02.006

[5] Bouziri, A., Ben, S.S., Hamdi, A., Menif, K., Belhadj, S., Khaldi, A., Kechaou, W., Kazdaghli, K. and Ben, N.J. (2007) Acute Respiratory Distress Syndrome in Infants at Term and near Term about 23 Cases. La Tunisiemedicale, 85, 874-879.

[6] Finn, D., De Meulemeester, J., Dann, L., Herlihy, I., Livingstone, V., Boylan, G.B., Ryan, C.A. and Dempsey, E.M. (2018) Respiratory Adaptation in Term Infants Following Elective Caesarean Section. Archives of Disease in Childhood. Fetal and Neonatal Edition, 103, F417-F421. https://doi.org/10.1136/archdischild-2017-312908

[7] Tochie, J.N., Choukem, S.P., Langmia, R.N., Barla, E. and Koki-Ndombo, P. (2016) Neonatal Respiratory Distress in a Reference Neonatology Unit in Cameroon: A Retrospective Analysis of Prevalence, Predictors, Etiologies and Outcomes. Pan African Medical Journal, 24, 152. https://doi.org/10.11604/pamj.2016.24.152.7066

[8] Rijal, P. and Shrestha, M. (2018) Scenario of Neonatal Respiratory Distress in Tertiary Hospital. Birth, 14, 6.

[9] Sivanandan, S., Agarwal, R. and Sethi, A. (2017) Respiratory Distress in Term Neonates in Low-Resource Settings. Seminars in Fetal and Neonatal Medicine, 22, 260-266. https://doi.org/10.1016/j.siny.2017.04.004

[10] Ayachi, A., Rigourd, V., Kieffer, F., Dommergues, M.A., Voyer, M. and Magny, J.F. (2005) Hyaline Membrane Disease in Full-Term Neonates. Archives de pédiatrie, 12, 156-159. https://doi.org/10.1016/j.arcped.2004.09.029 
[11] Kamble, M.B. and Jain, P. (2019) Meconium Aspiration Syndrome: Clinical Profile, Risk Factors and Outcome in Central India. International Journal of Contemporary Pediatrics, 6, 144. https://doi.org/10.18203/2349-3291.ijcp20185198

[12] Chowdhury, N., Giles, B.L. and Dell, S.D. (2019) Full-Term Neonatal Respiratory Distress and Chronic Lung Disease. Pediatric Annals, 48, e175-e181. https://doi.org/10.3928/19382359-20190328-01

[13] Ifarwati, T.W., Alamri, A.A., Alshahrani, M.A. and Al-Wassia, H. (2019) Incidence, Risk Factors and Outcome of Respiratory Distress Syndrome in Term Infants at Academic Centre, Jeddah, Saudi Arabia. Medical Archives, 73, 183-186. https://doi.org/10.5455/medarh.2019.73.183-186

[14] Ahmed, I.A., Hommadi, S.A., Raheem, S.A. and Murad, M.M. (2019) Early Respiratory Distress in Full Term Newborns. The Pharma Innovation Journal, 8, 638-644.

[15] Parkash, A., Haider, N., Khoso, Z.A. and Shaikh, A.S. (2015) Frequency, Causes and Outcome of Neonates with Respiratory Distress Admitted to Neonatal Intensive Care Unit, National Institute of Child Health, Karachi. Journal of Pakistan Medical Association, 65, 771-775.

[16] Seale, A.C., Blencowe, H., Manu, A.A., Nair, H., Bahl, R., Qazi, S.A., Zaidi, A.K., Berkley, J.A., Cousens, S.N. and Lawn, J.E. (2014) Estimates of Possible Severe Bacterial Infection in Neonates in Sub-Saharan Africa, South Asia, and Latin America for 2012: A Systematic Review and Meta-Analysis. The Lancet Infectious Diseases, 14, 731-741. https://doi.org/10.1016/S1473-3099(14)70804-7

[17] Tutdibi, E., Gries, K., Bücheler, M., Misselwitz, B., Schlosser, R.L. and Gortner, L. (2010) Impact of Labor on Outcomes in Transient Tachypnea of the Newborn: Population-Based Study. Pediatrics, 125, e577-e583. https://doi.org/10.1542/peds.2009-0314

[18] Jain, L. and Dudell, G.G. (2006) Respiratory Transition in Infants Delivered by Cesarean Section. Seminars in Perinatology, 30, 296-304. https://doi.org/10.1053/j.semperi.2006.07.011

[19] Zanardo, V., Simbi, A.K., Franzoi, M., Soldà, G., Salvadori, A. and Trevisanuto, D. (2004) Neonatal Respiratory Morbidity Risk and Mode of Delivery at Term: Influence of Timing of Elective Caesarean Delivery. Acta Paediatrica, 93, 643-647. https://doi.org/10.1111/j.1651-2227.2004.tb02990.x

[20] Kawaza, K., Machen, H.E., Brown, J., Mwanza, Z., Iniguez, S., Gest, A., Smith, E.B., Oden, M., Richards-Kortum, R.R. and Molyneux, E. (2016) Efficacy of a Low-Cost Bubble CPAP System in Treatment of Respiratory Distress in a Neonatal Ward in Malawi. Malawi Medical Journal, 28, 131-138.

[21] El Shahed, A.I., Dargaville, P.A., Ohlsson, A. and Soll, R. (2007) Surfactant for Meconium Aspiration Syndrome in Full Term/near Term Infants. Cochrane Database of Systematic Reviews, No. 3, CD002054. https://doi.org/10.1002/14651858.CD002054.pub2

[22] Jing, L., Yun, S., Dong, J.Y., Zheng, T., Li, J.Y., Lu, L.L., Liu, J.J., Liang, J., Zhang, H. and Feng, Z.C. (2010) Clinical Characteristics, Diagnosis and Management of Respiratory Distress Syndrome in Full-Term Neonates. Chinese Medical Journal, 123, 2640-2644.

[23] Dewez, J.E. and van den Broek, N. (2017) Continuous Positive Airway Pressure (CPAP) to Treat Respiratory Distress in Newborns in Low- and Middle-Income Countries. Tropical Doctor, 47, 19-22. https://doi.org/10.1177/0049475516630210 